\title{
Patologias em Piso de Concreto Armado Polido: Um Estudo de Caso
}

\author{
Title: Pathologies in Polished Concrete Floor: A Study Case
}

\author{
Maria Fernanda de Almeida Portela \\ Escola Politécnica de Pernambuco \\ Universidade de Pernambuco \\ 50.720-001 - Recife, Brasil \\ fernandaportela40@gmail.com
}

\author{
Carlos Wellington Pires Sobrinho \\ Escola Politécnica de Pernambuco \\ Universidade de Pernambuco \\ 50.720-001 - Recife, Brasil \\ carlositep@gmail.com
}

\begin{abstract}
Resumo O presente trabalho busca mostrar a necessidade de utilizar projetos executivos de pisos polidos de concreto, a fim de que sejam executados de forma a desempenhar o seu papel de acordo com a sua vida útil esperada sem apresentar patologias que possam vir a comprometer a sua durabilidade e utilização. Foi utilizado um estudo de caso, baseado em uma edificação vertical localizado na Região Metropolitana do Recife (RMR), confrontando os aspectos do piso aplicado in loco com as características semelhantes estudadas em outros estudos e artigos acadêmicos anteriores. Ficou evidente que para executar este tipo de elemento/revestimento deve-se seguir um projeto que atenda às cargas solicitantes e aos esforços a fim de prolongar sua utilização com o menor custo possível de manutenção.
\end{abstract}

Palavras-Chave: Projetos; Piso; Concreto; Patologias; Durabilidade; Manutenção

\begin{abstract}
This study aims to show the need for executive projects of polished concrete floors, so that they are executed in order to play its role according to their expected useful life without presenting conditions that may compromise their durability and use. For this we used a case study, based on a vertical building located in the Metropolitan Region of Recife (RMR), comparing the floor aspects applied in loco with similar traits in other previous studies and academic papers to this. It was evident, therefore, that to perform this type of element / coating must follow a project that meets loads applicants and efforts to extend its use at the lowest possible cost of maintenance.
\end{abstract}

Keywords: Project; Floor; Concrete; Pathologies; Durability; Maintenance 


\section{Introdução}

Junto ao crescimento imobiliário ocorrido a partir da última década, a utilização de diferentes tipos de revestimentos e acabamentos que pudessem trazer um aspecto refinado ao cliente final e que tivesse uma execução rápida por parte das construtoras, foi mais utilizado e em escalas maiores.

A escolha de executar pisos de concreto polido em áreas de estacionamento, no lugar de outros revestimentos largamente utilizados na década de 90 na região do Grande Recife, tem tomado maiores proporções à medida que os edifícios incorporaram novas tecnologias desde a sua concepção até a execução final. Deve-se também à flexibilidade que este material/sistema possui, no que se refere a maneira de aplicar e modelar para uma utilização específica.

No entanto, para este tipo de revestimento, a adoção de procedimentos padronizados e controlados de forma eficiente devem se apresentar de forma imprescindível a fim de que o desempenho esperado para uma determinada vida útil seja atingida. Dessa forma, é importante ressaltar que a utilização dos materiais e de processos executivos inadequados interferem diretamente no aspecto do produto acabado.

A busca pela redução de custos por parte das empresas construtoras interfere diretamente nesse aspecto, sob o ponto de vista de que em muitos dos casos, por ser constituído basicamente por um material construtivo largamente utilizado na construção civil, o concreto. Acredita-se, em grande parte deles, que este pode ser aplicado da mesma forma que em outros sistemas, descartando muitas vezes a existência de um projeto específico para este fim.

Devido a este tipo de prática, entre outras, os pisos de concreto polido podem apresentar diversos tipos de patologias, sejam desde danos estéticos até a inutilização do local onde irão trafegar pessoas e veículos. No entanto, para cada caso há diferentes causas, e como tais diferentes formas de tratamento/recuperação.

Sendo assim, serão apresentados alguns tipos de patologias ocorridas em piso de concreto polido aplicado em uma edificação vertical da Região Metropolitana do Recife (RMR), de modo que sejam citadas as suas possíveis causas a fim de evidenciar a necessidade de utilizar projetos adequados [1], baseados nas normas mais atuais, para uma execução correta desse tipo de revestimento.

\section{Referencial Teórico}

Segundo Camargo [2], os pisos cimentícios devem apresentar propriedades e requisitos mínimos de desempenho como resistência mecânica, capacidade de absorver deformações, estanqueidade, resistência a agentes químicos e durabilidade, entre outros.

Para atender a todas as propriedades citadas, é preciso antes de qualquer análise e ponto de partida de projeto, definir a que uso tal elemento vai se destinar. Cada uso implicará em diferentes solicitações, no que diz respeito aos esforços, implicando em diferentes resistências e consequentemente elementos aplicados em cada tipo de estrutura.

Além de analisar o elemento piso de concreto isoladamente, é necessário estudar o solo utilizado como base de assentamento, o qual deverá suportar as solicitações propostas para cada sistema de piso.

Cuidados como adensamento das camadas de solo sobre o qual se assentará o piso de concreto, nivelamento da camada, espessura suficiente para suportar a carga solicitada em projeto, aplicação de lona plástica entre o substrato e o concreto, aplicação de tela metálica para distribuir as cargas e utilização de barras de transferência para as juntas de dilatação, são medidas que levam a uma redução na probabilidade de aparecimento de fissuras [3].

Segundo Gasparetto [4], o projeto define a execução, tendo a mesma, sem ele, caráter de improviso com resultado final duvidoso. Devendo dessa forma, de acordo com o uso a que se destina, o projeto ser feito considerando todos os agentes atuantes antes, durante e depois da execução deste piso a fim de que este tenha durabilidade prolongada.

Todos cuidados tomados desde a fase de projeto até a execução não eliminam por completo o aparecimento de patologias, pois além destes pontos a composição do concreto pode implicar também em patologias posteriores à execução. Mesmo com uma vida útil prolongada, cada material utilizado em sua execução possui vida útil limitada, podendo ainda assim apresentar sinais de desgaste que não podem aparecer de forma precoce, mas que se não utilizados dentro dos limites estabelecidos, os materiais podem apresentar sinais de que necessitem ser substituídos.

De acordo com a revista Rodrigues [5] e Koslinski [6], entre as possíveis patologias que venham a se apresentar nos mais variados tipos de piso polido de concreto, tem-se como as mais comuns: fissuras, desgaste e esborcinamento de juntas. No que se refere as fissuras, as causas ligadas à execução podem se dar por atraso no corte das juntas, exsudação natural ou excessiva da água contida no concreto, cura inadequada (causando a retração por secagem), armaduras mal posicionadas (para combater a tração), problemas no acabamento e por má compactação 
do solo, podendo esta última levar a fissuras de caráter estrutural. Estas últimas, por sua vez, representa a minoria dos casos de fissura em piso, pois apresenta maior preocupação por parte dos projetistas e executores.

Quanto ao desgaste, normalmente, ainda segundo a revista, a dosagem do concreto, ou seja, a sua qualidade, tem papel fundamental neste tipo de patologia, fator que pode ser agravado pelo tempo de pega que, atualmente tem aumentado para uma execução mais tranquila por parte daqueles que a fazem.

Já o esborcinamento de juntas (Figuras 1 e 2) é retratado tendo como causa principal a ausência das barras de transferência, erros em seu posicionamento e até mesmo atraso no corte dessas juntas. A determinação do local nos quais essas juntas devem ser executadas, a distância entre as mesmas e o seu preenchimento, devem ser determinados em projetos, a fim de que sejam evitadas fissuras dessa natureza.

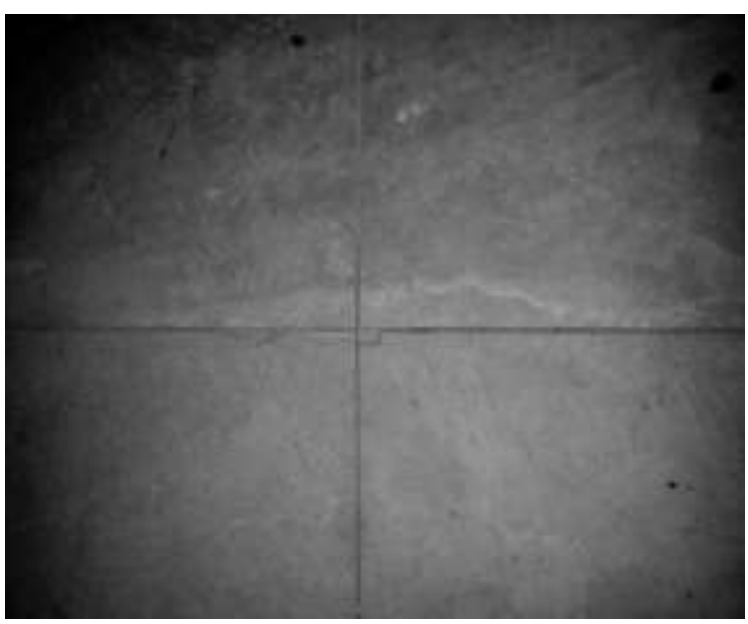

Figura 1: Esborcinamento de juntas.

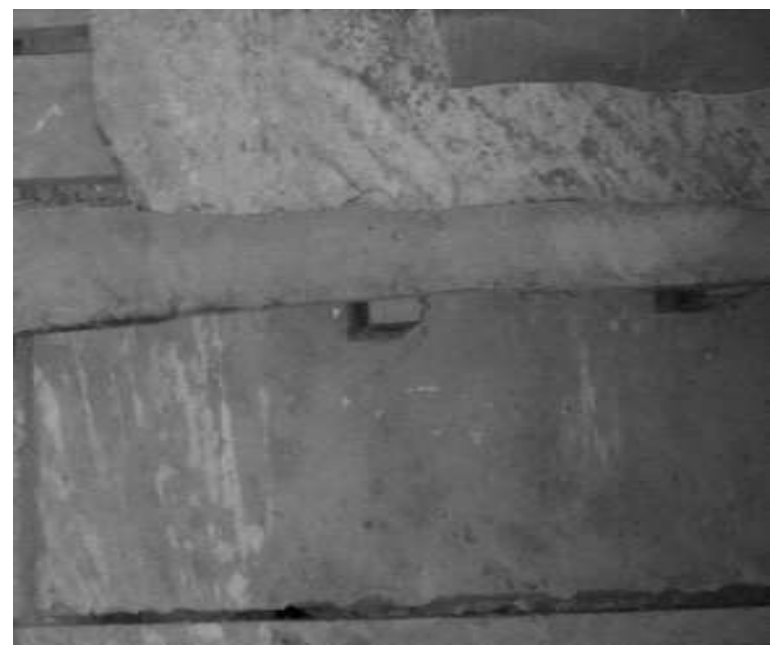

Figura 2: Esborcinamento de juntas.

\section{Exsudação e retração como fatores causadores de patologias}

\subsection{Exsudação}

A exsudação é um fenômeno que pode ocorrer nas primeiras idades do concreto e se refere basicamente à separação de parte da água contida na mistura, sendo esta deslocada para a superfície, aumentando dessa forma à relação água/cimento no local afetado. A sua ocorrência , de acordo com Rocha et al [9] pode se dever à vibração e acabamento excessivo do concreto.

Devido ao aumento da relação a/c na superfície da área concretada, o aparecimento de patologias como as fissuras de assentamento plástico e o desgaste.

As primeiras, ocorrem durante a concretagem, na qual a água passa a preencher a parte envolta da armadura no lugar do concreto, e esta, posteriormente, percola até a superfície, sendo um local propício ao aparecimento de fissuras. No entanto, outros fatores podem tornar a superfície concretada mais vulnerável à ocorrência deste tipo de patologia, como por exemplo a bitola da armadura utilizada. Os processos externos, como a atuação da luz solar que aquece o concreto aumentando a saída de água do mesmo não influenciam nesse processo, pois a água referente à exsudação diz respeito apenas àquela que se deslocou durante a concretagem.

O desgaste, por sua vez, além de outras motivações pode se dever também à exsudação, pois, a água acumulada na superfície ocasiona a redução de resistência da região, quando comparado às camadas inferiores, levando esta área a apresentar desgaste com mais facilidade. Isto ocorre porque a relação água/cimento define a resistência mecânica do concreto, e à medida que esta relação aumenta, a resistência do concreto diminui deixando-o mais susceptível ao desgaste quando submetido a algum tipo de solicitação.

\subsection{Retração}

A retração do concreto, diferentemente da exsudação, sofre a influência dos fatores climáticos, como o calor e a variação de umidade, pois afetam diretamente a variação volumétrica da peça concretada, levando ao aparecimento de tensões de tração e compressão durante o tempo ao qual está submetida.

Dentre os tipos de físsuração causados por retração, o aparecimento de patologias pode se dar em duas fases: no concreto endurecido e no estado plástico. Neste último o aparecimento de fissuras tem maior propensão a ocorrer devido à perda de água.

Segundo Rocha et al [9] a retração plástica se divide em quatro fases diferentes. São elas: assentamento plásti- 
co, retração plástica primária, retração autógena e retração plástica secundária.

O primeiro refere-se a exsudação, ou seja, as partículas de água sobem para a superfície por percolação após o assentamento do concreto e lá repousam, propiciando posteriormente $\mathrm{o}$ aparecimento de fissuras.

A segunda é aquela que ocorre quando a atuação dos fatores climáticos influencia na evaporação, ou seja ela se dá exclusivamente com a sua atuação associada à presença da água na superfície. No entanto, este fenômeno não ocorre apenas antes da pega, ele atua também durante a pega tendo como fator primordial que a taxa de evaporação seja maior que a de exsudação (Figura 3).

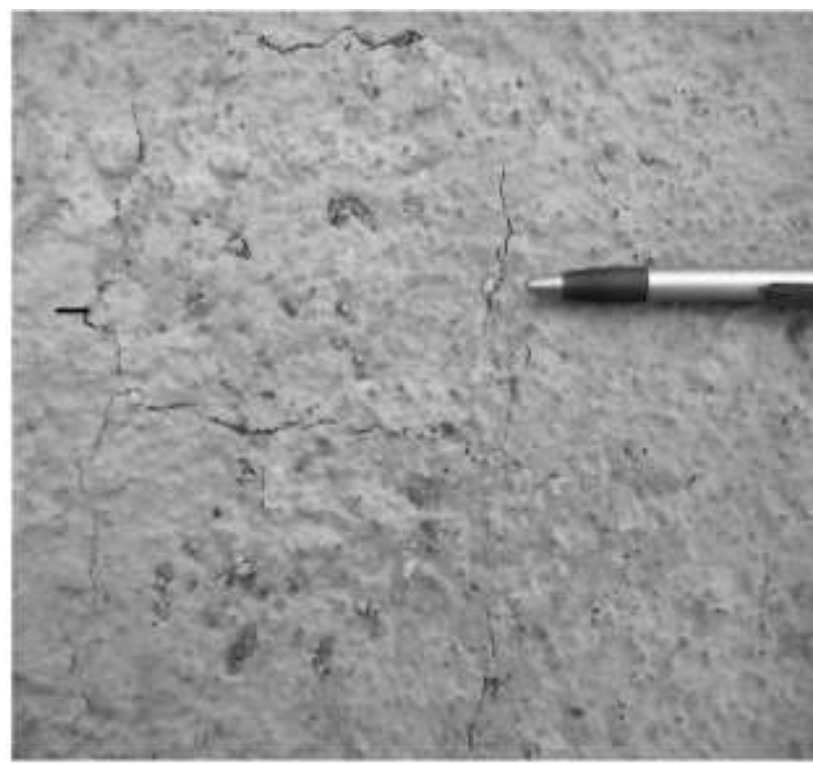

Figura 3: Retração por secagem. [10].

A retração autógena, definida por Rocha et al [9], é a retração que ocorre sem troca de massa com o meio ambiente, ou seja, sem que exista perda de água. Esta retração se dá quando a hidratação do concreto de desenvolve e os produtos envolvem os agregados, mantendo todos unidos. Assim, os níveis de capilaridade, o assentamento plástico e a retração plástica primária decrescem. Tal fenômeno ocorre quase que totalmente após a pega do concreto. Atualmente leva-se muito em consideração este estágio, tendo em vista que a relação água/cimento apresenta níveis muito baixos.

Já na fase de endurecimento do concreto, a retração plástica diminui e quase não se faz mais presente, por isso sendo chamada de retração plástica secundária (Figura 4), finalizando as quatro fases de retração. Esta, por ocorrer na fase em que o concreto está apresentando ganho de resistência mecânica, as fissuras não surgem em grande número neste momento, e por isto, apenas as três fases citadas acima são as mais comuns.

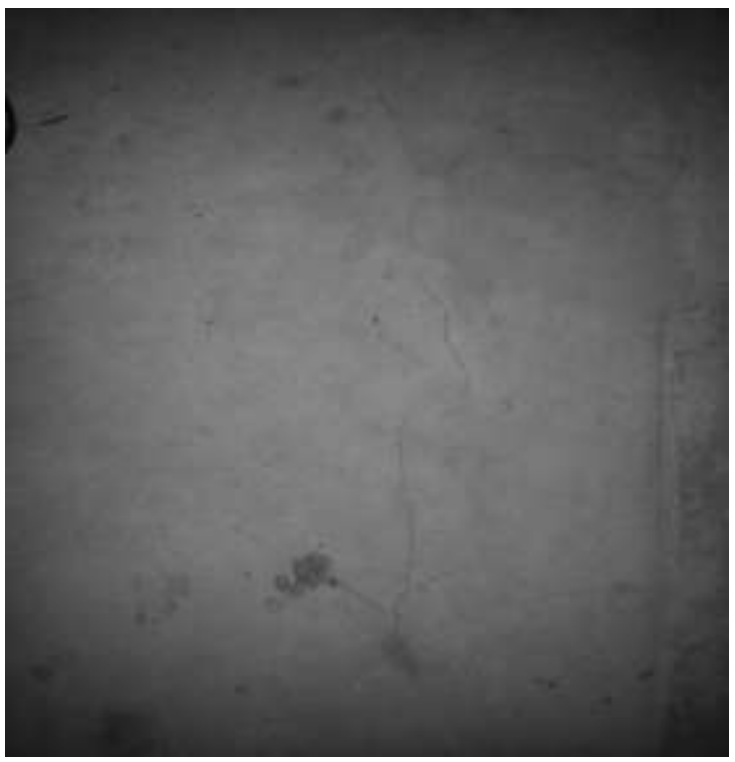

Figura 4: Retração após a fase de endurecimento do concreto.

\section{Utilização de fibras}

$\mathrm{O}$ uso de fibras tem sido utilizado em larga escala em diferentes materiais para obter os materiais chamados de compósitos. Estes, são materiais nos quais dois compostos diferentes, quando juntos, formam um novo material com algumas propriedades diferentes daquelas que $o$ materiais individuais não apresentavam enquanto não tinham sido unidos.

Segundo Figueiredo [11], compósitos, como já diz o nome, são materiais compostos basicamente por duas fases: a matriz e as fibras. As fibras podem atuar como um reforço da matriz em função das propriedades deste e das próprias fibras. Tais como concreto, composto por uma fase agregado e outra fase pasta, que é a matriz, cujo comportamento consiste na combinação das propriedades dos materiais que o constituem.

Ainda de acordo com Figueiredo [11], as fibras de polipropileno, nylon e polietileno podem ser classificadas como fibras de baixo modulo, que restringe sua aplicação ao controle de fissuração quando as matrizes possuem baixo modo de elasticidade, como é o caso de retração plástica em argamassas.

Dessa forma, é possível inferir que as fibras tem, quando utilizadas junto ao concreto, a função de controlar a fissuração, principalmente aquelas provenientes de retração.

Como medida de evitar a fissuração por exsudação, as fibras de polipropileno aplicadas junto ao concreto atuam no impedimento da saída de água para a superfície (Figura 5), fato que reduz o aparecimento de fissuras causadas 
por assentamento plástico. Como consequência, por não haver deslocamento de água para a superfície concretada na mesma proporção na qual o concreto que não possui fibras em sua composição, o desgaste por abrasão também tem ocorrência reduzida. Fato este que ocorre pois, não há perda tão significativa da resistência das camadas superficiais, conferindo às camadas superiores maior resistência mecânica quando comparadas ao concreto em seu estado normal.

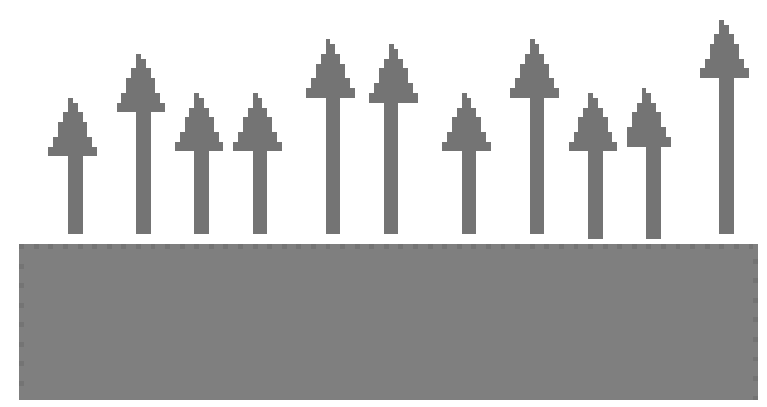

Figura 5: Saída de água para a superfície sem utilização de fibras.

As fibras não absorvem água, e portanto não retém a água em seu interior. Elas atuam no sentido de formar barreiras que impedem a saída de água em grande quantidade para a superfície, permitindo que a água fique no concreto (Figura 6), durante o período de hidratação do cimento por mais tempo. Dessa forma, permite que os compostos sejam formados antes do aparecimento de possíveis patologias.

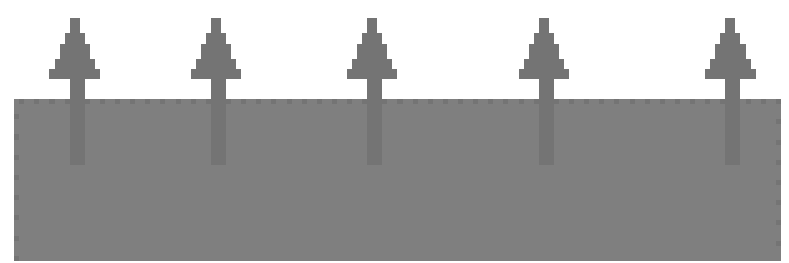

Figura 6: Saída de água para a superfície com utilização de fibras.

Na retração a utilização de fibras de polipropileno tem papel fundamental na redução do aparecimento de fissuras devido às causas relacionadas a tal fenômeno que ocorre em concretos submetidos a diferentes condições climáticas, principalmente na sua fase plástica.

O aparecimento de fissuras, neste caso, começa a se dar quando o concreto vai passando do seu estado fresco para o endurecido, ou seja, com a pega do cimento. Nesse estado o concreto vai perdendo a sua fluidez e com isso a sua capacidade de deformação também se reduz. Quando por influência de condições de temperatura, entres outros fatores, a água proveniente da exsudação evapora, iniciase o aparecimento de fissuras, pois o concreto passa a não absorver mais as deformações solicitadas, demonstrando patologias.
Segundo Rocha et al [9], as fibras de polipropileno (Figura 7) de baixo módulo, ao adicionado no concreto, torna o mesmo mais maleável nas primeiras idades. Esta propriedade da fibra é transmitida ao concreto, que passa a trabalhar de forma eficaz a deformação por retração. Desta forma, as fissuras são controladas e, em alguns casos, até totalmente contidas.

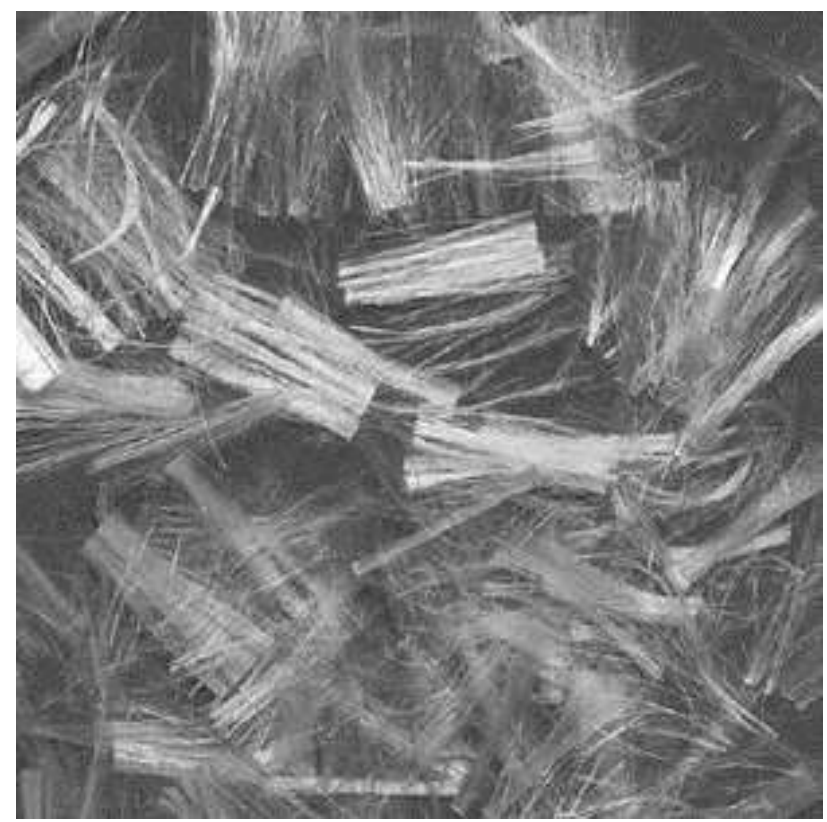

Figura 7: Fibras de polipropileno [12].

Para obter resultados satisfatórios, o tipo da fibra, seu tamanho, espessura e módulo de elasticidade junto às propriedades do concreto têm que ser estudadas a fim de que se obtenha um material final (compósito), com características as quais sejam capazes de absorver fissuras sem prejudicar a aparência e a utilização da estrutura de concreto durante a sua vida útil.

Tendo como pressuposto estes parâmetros de utilização atuando junto a outros elementos que evitam o aparecimento de patologias, como as barras de transferência e as telas soldadas por exemplo, é que pode-se chegar a uma estrutura final com menor probabilidade de aparecimento de patologias

\section{Metodologia}

Para a apresentação de algumas das patologias citadas anteriormente e demonstrar as possíveis causas das mesmas, foi utilizado como estudo de caso o piso de concreto polido executado em uma edificação vertical situada na Região Metropolitana do Recife (RMR), por empresa terceirizada a uma construtora de médio porte. Para tal, será tomada como base as características do piso in loco, registradas através de fotografias, as quais evidenciam os sintomas patológicos do sistema. 
Inicialmente foram coletados dados relativos a todas as etapas de construção deste elemento. Os mesmos englobam desde a escolha de utilizar ou não utilizar projetos, passando pela definição dos seus materiais constituintes baseados em experiências anteriores, até a escolha da mão-de-obra e fornecedor que irão participar da execução do piso na etapa de execução propriamente dita e o seu aspecto final.

A fim de identificar as possíveis causas dos problemas encontrados, foram tomados como base artigos científicos e monografias que tratam do tema de forma aprofundada e generalizada no que se refere aos mais diversos tipos de patologias. Para embasamento técnico, foram utilizadas as normas técnicas: NBR 6118 [7] e DNIT [8].

\section{Estudo de caso}

\subsection{Anamnese do problema}

A edificação trata-se de um edifício de uso empresarial, o qual consta de 01 (um) pavimento térreo, 01 (um) pavimento pilotis, 05 (cinco) pavimentos tipo e 01 (um) pavimento convenções. O piso de concreto polido foi executado apenas no pavimento térreo com a finalidade de abrigar as vagas de garagem relativas às salas comerciais e foi executado a cerca de 01 (um) ano.

Atualmente a obra encontra-se em execução, estando na fase de acabamento. Decidiu-se executar o piso antes de aplicar os revestimentos devido à logística na distribuição de suprimentos na obra. A necessidade de estocar materiais no pavimento térreo, por possuir uma área relativamente pequena para este fim foi o principal fator que levou a escolha da execução fora dos padrões convencionais de cronograma físico.

Além do estoque de materiais, o piso também é utilizado para abrigar parte das instalações provisórias como a sala de segurança do trabalho, o estoque de EPI's (equipamentos de proteção individual), refeitório e almoxarifado.

O piso foi construído sem elaboração de projeto, sendo sua execução baseada em obras anteriormente entregues. A concretagem de placas executadas em datas diferentes foi feita devido à escolha particular da administração, não tendo relação com procedimentos baseados em normas.

Sendo assim, o piso apresenta como principais patologias a presença de fissuras, a diferença de nível entre diferentes placas.

\subsection{Diagnóstico das manifestações patológicas en- contradas}

Inicialmente foram coletadas informações a respeito das condições nas quais o piso foi planejado e executado para que a partir dessas informações fosse possível inferir quais são as possíveis causas das patologias encontradas.

A construtora informou que não foi adotado nenhum projeto para execução do piso, definindo apenas, com base em execuções anteriores a melhor forma de aplicação. Os requisitos adotados, portanto, apresentam falhas na idealização dos materiais empregados e das técnicas necessárias para um bom desempenho.

Armações como aquelas que fazem a ligação entre as diferentes etapas de concretagem, a definição dos locais de corte de acordo com o trabalho que o piso necessita, o retardo no tempo de execução das juntas e até mesmo a resistência característica do concreto (fck) são fatores determinantes para que futuras patologias possam se desenvolver.

Por não ter projeto definido, alguns elementos, os quais foram citados acima, não foram utilizados durante a execução e a presença de patologias se deu assim que o piso passou a ser solicitado por cargas provenientes do armazenamento de materiais, como cerâmicas e materiais ensacados, por exemplo.

Dentre os problemas encontrados pode-se desta-car a presença de fissuras (Figura 8) e a diferença de nível entre as placas executadas (Figura 9). A detecção das possíveis causas se deu por meio de observação juntamente às informações do processo executivo fornecido pela construtora.

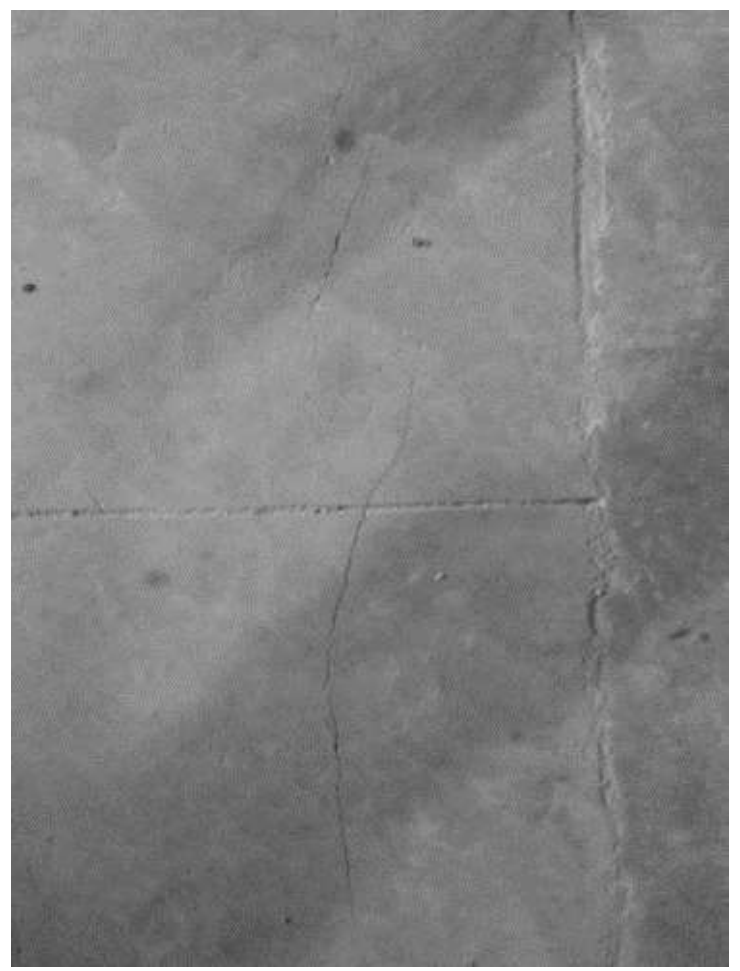

Figura 8: Presença de fissuras na emenda entre duas concretagens. 


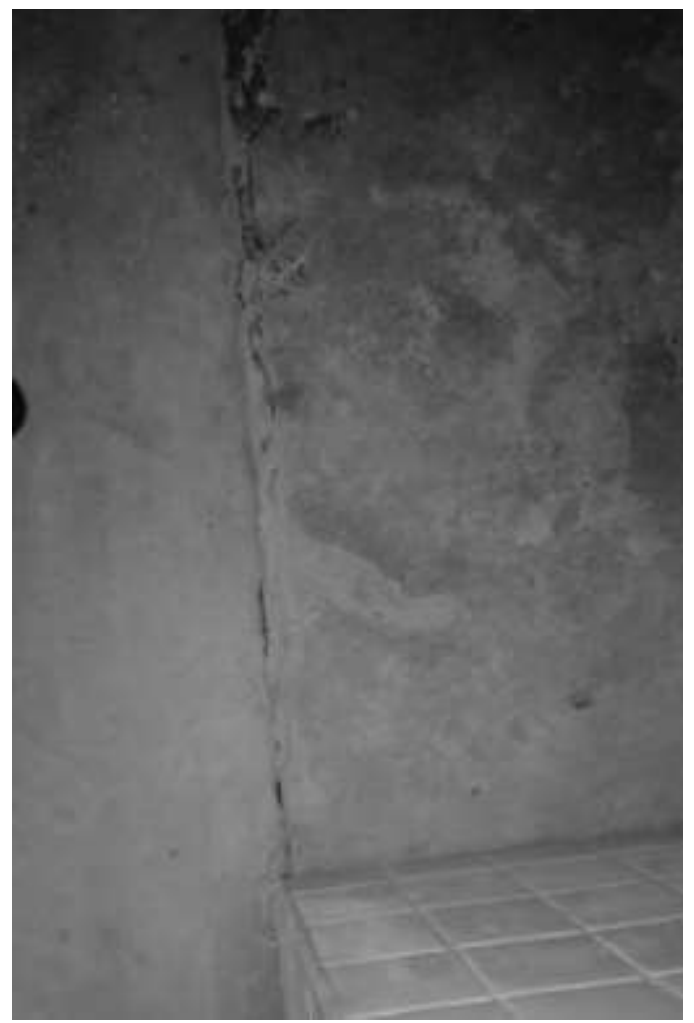

Figura 9: Diferença de nível entre duas placas.

De acordo com a construtora, não foram aplicadas barras de transferência entre as diferentes concretagens e consequentemente entre placas diferentes, sendo uma possível causa para o aparecimento de fissuras paralelamente ao elo de ligação entre as mesmas e para o surgimento de um "degrau" entre placas diferentes. No entanto, para este último caso, apenas a não aplicação das barras não seria suficiente para a diferença de nível entre as mesmas, e ao ser questionada a construtora informou que em uma das placas (a primeira a ser executada) foi aplicada carga temporariamente, a qual não foi prevista para a utilização da mesma, ocasionando, portanto, tal patologia.

Entretanto, outras fissuras, com diferente característica da citada anteriormente também foram encontradas (Figura 10). Estas por sua vez, conservaram o fato de surgir a partir de quinas, sejam elas a partir de quinas reentrantes tanto nos limites de concretagem como em locais em que se encontram as tampas para caixas de inspeção. Para estes casos, verificou-se que não foram aplicadas barras perpendiculares às quinas, para assim combater os possíveis esforços que surgem nessa direção. Em contrapartida nos pilares a construtora fez a aplicação, e sendo assim não surgiram fissuras nesses locais.

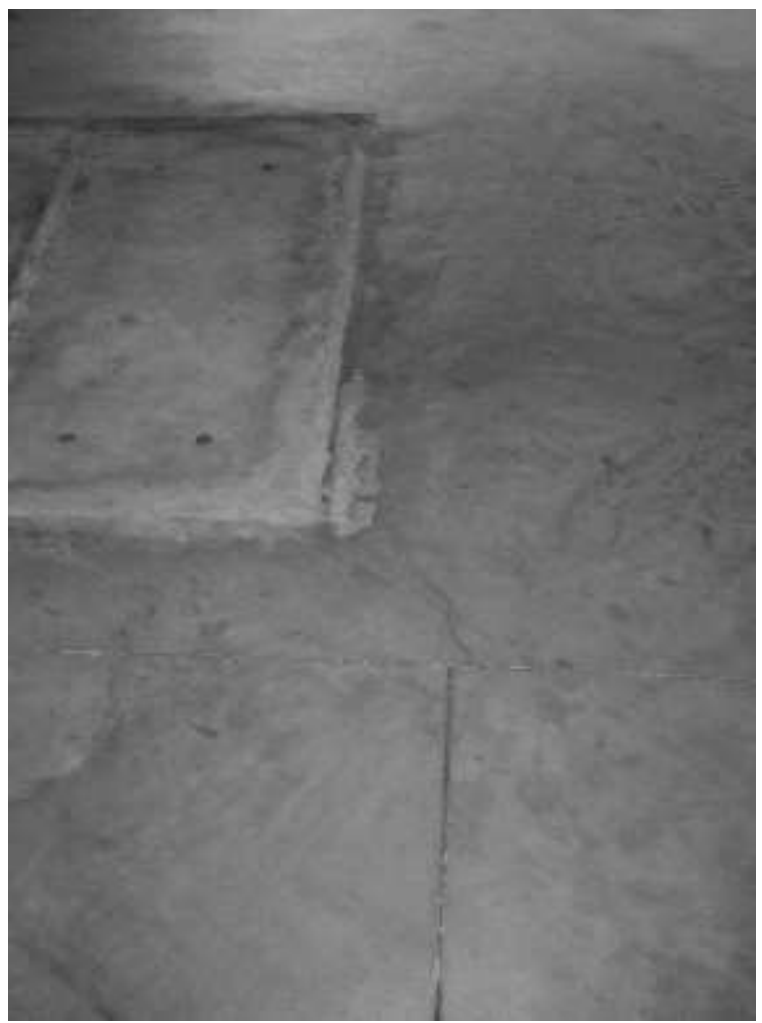

Figura 10: Fissura a partir de quinas reentrantes.

O último tipo de fissura encontrada foi aquela localizada com surgimento e fim a partir de juntas cerradas. Segundo a construtora houve atraso no corte da mesma por pelo menos um mês, o que, de acordo com a bibliografia consultada é uma possível causa do surgimento dessa patologia, a qual se apresenta logo após ao corte retardado do piso.

\section{Considerações finais}

Dentre as manifestações patológicas observados no piso de concreto armado polido, as que se apresentam em maior intensidade são as fissuras e diferenças de nível entre as placas executadas em datas diferentes.

A ausência de algumas armaduras, a não utilização de fibras e o retardo no corte das juntas de concretagem são as mais prováveis causas do aparecimento dessas patologias nos pontos indicados anteriormente.

Dessa forma, é notória que a falta de um projeto com especificações de materiais e posicionamento das estruturas inerentes a execução desse projeto é de extrema necessidade, tendo em vista que se houvesse um projeto determinado para tal obra e o mesmo fosse seguido de acordo com as normas técnicas, respeitando elementos que levam a um desempenho mínimo dessa estrutura, tais patologias poderiam ter sido evitadas. 


\section{Referências}

[1] D.F. OLIVEIRA. Levantamento de causas de patologias na construção civil. Trabalho de conclusão de curso, Universidade Federal do Rio de Janeiro (UFRJ). Rio de Janeiro, 2013.

[2] M. F. S. CAMARGO. Pisos à base de cimento: caracterização, execução e patologias. Monografia, Universidade Federal de Minas Gerais (UFMG). Belo Horizonte, Minas Gerais, 2010.

[3] F.C.B. SILVA. Sistemas construtivos de piso de concreto industrial com altos índices de planicidade (Ff) e de nivelamento ( $\mathrm{Fl})$. Trabalho de conclusão de curso, Universidade Anhembi Morumbi. São Paulo, 2009.

[4] W.E. GASPARETTO. Recuperação no chão. Revista Téchne, Edição 154. 2010.

[5] P. P. F. RODRIGUES. Piso novo. Revista Téchne, Edição 114. 2006.

[6] M. KOSLINSKI, et al. Manifestações patológicas em pisos industriais. Revista eletrônica FACEAR, Faculdade Educacional Araucária, Volume 1. Curitiba, Paraná. 2013.

[7] NBR 6118. Projeto de estruturas de concreto Procedimento. Associação Brasileira de Normas Técnicas (ABNT). 2007.

[8]

Norma DNIT 049/2004. Pavimento rígido Execução de pavimento rígido com equipamento de forma deslizante - Especificação de serviço. Departamento Nacional de Infraestrutura de Transportes. 2004.

[9] ROCHA, L. F. P.; JUNIOR, E. S. D. Estudo de concreto com adição de fibra de polipropileno para controle da fissuração. Trabalho de Conclusão de Curso. Universidade da Amazônia. Belém. 2011.

[10] Retração por secagem. Disponível em: http://propriedadesdoconcreto.blogspot.com.br/2 $\underline{012 / 10 / \text { fissuras-em-lajes-sintomas- }}$ parecidos.html 26/08/2016. Acessado em: 25/08/2016.

[11] FIGUEIREDO, A. D. Concreto com Fibras de Aço. Boletim Técnico. Escola Politécnica da Universidade de São Paulo, 2000.
[12] Fibras de polipropileno. Disponível em: http://www.vedacamp.com.br/site/documento_5 5 0 fibra-de-

polipropileno.html?PHPSESSID=f7c16aea7bfb6528fe179a 93f3c8d3f0. Acessado em: 25/08/2016. 